\title{
O GRUPO ESCOLAR CÔNEGO ÂNGELO: DE VOLTA AOS PARDIEIROS? (Ituiutaba-MG: 1964-1985)
}

\author{
Sauloéber Tarsio de Souza (UFU) \\ Talita Alves Costa (UFU) ${ }^{1}$
}

\section{RESUMO}

O texto apresenta o processo de criação e consolidação do então Grupo Escolar Cônego Ângelo no município de Ituiutaba, Triângulo Mineiro, na década de 1960. Implantado no período da Ditadura Civil-Militar, tinha o objetivo de atender as classes populares, assim como os primeiros grupos escolares republicanos do início do século $\mathrm{XX}$, contudo, as condições de sua criação divergiram substancialmente da trajetória dos palácios da instrução (FARIA FILHO, 2000), já que foi conduzida de forma precária sem sede própria, mobiliários e materiais didáticos adequados. No percurso de investigação, além das motivações para sua constituição, estudamos os perfis de alunos, docentes, e algumas práticas no cotidiano dessa escola, assim, analisamos conjunto de fontes compostas por livros de matrículas, publicações oficiais e iconografia, além do recurso a história oral. A falta de planejamento e a precariedade das primeiras décadas de sua existência representaram ao mesmo tempo, a oportunidade de escolarização dos filhos de grupos sociais ainda fora da escola.

Palavras-Chave: Grupo Escolar Cônego Ângelo; Triângulo Mineiro; História de Instituições Escolares.

\section{THE SCHOOL GROUP CANON ÂNGELO: BACK TO PARDIEIROS?}

\section{ABSTRACT}

The paper presents the process of creation and consolidation of the School Group Canon Angelo in the municipality of Ituiutaba, Triangulo Mineiro (Brazil), in the 1960s . Deployed during the Civil-Military Dictatorship, was intended to meet the popular classes, as well as the first republican school groups from the early twentieth century, however, the conditions of its creation diverged substantially from the trajectory of the palaces of the instruction (FARIA FILHO, 2000), as it was conducted with precariously, appropriate furniture and teaching materials. In the course of investigation, in addition to the reasons for its formation, we studied the profiles of students, teachers, and some practices in the everyday life of this school, thus we analyzed a font set consisting of books files, official publications and iconography, besides the use of oral history. The lack of planning and precariousness of the first decades of its existence represented at the same time, the opportunity of education for the children that were still out of the schools.

Keywords: School Group Canon Ângelo; Triângulo Mineiro; History of School Institutions. 


\section{Introdução}

O Grupo Escolar Cônego Ângelo foi implantado no município de Ituiutaba (Triângulo Mineiro) na década de 1960 e seria consolidado apenas nos anos de 1980 quando recebeu sua sede própria. Desde o início, construiu-se em torno desta escola a ideia de que seria uma instituição voltada para atender as classes populares, imagem que se projetou ao longo de todo o processo de formação da identidade do então grupo escolar (mais tarde escola estadual). Tal imaginário foi formatado localmente no período do governo militar (1964-1985), contexto marcado por políticas de massificação da educação básica, uma grande "empreitada civilizatória" para inserir no sistema escolar os grupos sociais até então fora da escola.

Desse modo, justifica-se parcialmente a pesquisa pelo caráter marginal do objeto em estudo, já que representa tema pouco explorado no campo da História da Educação em geral e, em particular na subárea da História das Instituições Escolares. Segundo Buffa e Nosella (2009, p.25), as escolas de formação para o trabalho e as mais modestas destinadas à população carente, como escolas comunitárias ou de caráter assistencial estão pouco representadas nesses estudos. Outro argumento favorável a investigação realizada, é a necessidade de se diferenciar a trajetória dos primeiros grupos escolares criados no início da república e pensados como palácios da instrução (FARIA FILHO, 2000) da realidade dos grupos escolares surgidos a partir dos anos de 1950, no período conhecido como segunda República, muito embora ambos tivessem o objetivo declarado de escolarizar as massas, as condições infraestruturais na criação dessas escolas foram distintas nos dois momentos históricos distantes em mais de meio século.

Metodologicamente, adotamos, além da revisão bibliográfica, a consulta ao acervo da escola para o levantamento de informações junto aos livros de matrículas, caderno de promoção de alunos, algumas matérias jornalísticas, publicações oficiais e iconografia, também nos apoiamos em fontes orais recorrendo a depoimentos de ex-alunos, exprofessores e ex-diretores (identificados com nomes fictícios). Ainda sobre os procedimentos metodológicos, ao estudar uma determinada instituição escolar é necessário se observar a relação entre o contexto e o interior das instituições, vejamos:

A dimensão da identidade de uma instituição somente estará mais bem delineada quando o pesquisador transitar de um profundo mergulho no micro e, com a mesma intensidade, no macro. As instituições não são recortes autônomos de uma realidade social, política, cultural, econômica e educacional. Por mais que se estude o interior de uma instituição, a explicação daquilo que se constata não está dada de forma imediata em si mesma [..] as instituições adquirem uma identidade, esta é fruto dos laços de determinações externas a elas [..]. (SANFELICE, 2006, p.78).

Dessa maneira, cabe ao pesquisador buscar o sentido dessa identidade na relação do particular com o geral. Para realizar um estudo de cunho historiográfico é preciso imergir no interior da instituição pesquisada, com uma visão aguçada, buscando as suas origens, seu desenvolvimento ao longo do tempo, as transformações ocorridas no prédio da instituição, além de se pensar sobre a identidade dos sujeitos que estão inseridos neste espaço, e quais as práticas ali realizadas. É preciso destacar que a história de uma instituição em particular, reflete a história da educação de determinado recorte temporal e de um determinado espaço como um todo. 
É inegável a importância de se conhecer as especificidades de cada instituição, já que são entidades veiculadoras e mediadoras de ações culturais, que expressam os conflitos de determinada sociedade, sendo permeadas por relações de domínio e instâncias de resistência à dominação. No entanto, reafirmamos, o historiador da educação deve pesquisar o explícito e o implícito nesses espaços, sem esquecer dos seus vínculos com o contexto econômico, político, social e cultural (SOUZA; CASTANHO, 2009, p.15).

O pesquisador da história de uma instituição deve buscar criar uma realidade dissertativa e original sobre o seu passado, fazendo um esforço de levantamento de fontes e valores vividos transformando-os em valores do presente e de valorização de certo âmbito social.

\section{Grupos Escolares em Minas Gerais e no Pontal do Triângulo}

A criação dos grupos escolares em Minas Gerais também teve como objetivo, substituir as cadeiras isoladas de instrução primária e enfrentar a questão do elevado índice de analfabetismo, problema herdado do regime imperial. Segundo Araujo e Souza (2012, p. 22), o número de analfabetos no país ultrapassava os $80 \%$ em 1890 e andava em torno de $65 \%$, conforme estimava, em 1930.

No Estado de Minas Gerais, o governo de João Pinheiro (cujo secretário da instrução era Delfim Moreira), já no regime republicano, tomou medidas no sentido de se educar as massas de analfabetos. A multiplicação de instituições escolares deveria atender a população infantil, educando-a a partir de princípios ditos modernos e racionalistas. Dessa maneira:

Os grupos escolares foram concebidos como ideal de escola moderna popular, com o ensino graduado e racionalizado, classes seriadas e divididas por idades e grau de adiantamento das crianças, ensino simultâneo, método intuitivo, prédios para acomodar tal estrutura, instalações e mobiliários construídos segundo preceitos higienistas, predomínio de disciplinas de caráter científico, aulas de ginástica, música e trabalhos manuais. (ARAÚJO; SOUZA, 2012, p.18)

Com tal orientação, em 1906, João Pinheiro colocaria em andamento uma ampla reforma educacional, cuja maior inovação seria a implantação dos grupos escolares criados como símbolo da escola republicana urbana em oposição às escolas isoladas que predominavam no campo, administradas por um único professor que representava, então, o próprio saber. No Triângulo Mineiro, tendo como parâmetro a data de criação dessas escolas, surgiram 21 grupos escolares entre os anos de 1908 e 1932, devendo tais instituições, também nessa região mineira, materializar a moderna educação.

A educação oferecida nessas novas instituições deveria obedecer ao principio do que se considerava expressão da moderna pedagogia: o ensino intuitivo considerado o método adequado à realidade nacional, e que assegurava às classes populares os conhecimentos mínimos e necessários à vida moderna. (ARAUJO; SOUZA, 2012, p.22) 
Para uma nova proposta educacional cujo suporte seria uma rede de escolas públicas, o governo criou também uma estrutura de fiscalização e controle, assim, surgiu o sistema de inspeção escolar dividido em dois eixos: o técnico e o administrativo, com o intuito de controlar e modelar os serviços de docência e de inspeção em conformidade ao modelo escolar que se desejava em Minas Gerais (ISOBE, 2012). Mesmo assim, boa parte das crianças continuava fora das escolas, já que, em geral, nos municípios do estado havia apenas um grupo escolar o que não era suficiente para atender ao elevado crescimento demográfico, assim, nas primeiras décadas da república a tarefa educacional pública beirava a caos, pela incapacidade do estado de financiar a educação.

Faria Filho (2000) ao analisar esse movimento de renovação da educação primária na capital mineira, afirma que os novos conteúdos escolares eram entendidos como fundamentais para a consolidação de uma cultura urbano-industrial, assim a disciplina e a obediência seriam pilares para se atingir a racionalidade pretendida com os grupos escolares. O seu foco foi o grupo escolar enquanto forma autorizada ou simbolismo atrelado ao moderno que deveria se opor às escolas isoladas entendidas como expressão do atraso brasileiro, por isso a lógica seria a de implantar "palácio, no centro da cidade, pardieiro no subúrbio, (...)" (NUNES, 2002, p.165).

Como consequência, esses palácios da instrução se multiplicaram pelo estado mineiro e pelo país, mas nunca em quantidade suficiente para atender a demanda. Isso porque com o fim da segunda grande guerra e início de novo período democrático no país, acelerou-se a expansão da rede pública de ensino, especialmente a partir dos anos de 1950, visando atender a população que se avolumava nas cidades com o fenômeno da urbanização que elevaria a pressão por escolas. Contudo, a trajetória desses novos grupos escolares seria bastante distinta das primeiras instituições públicas criadas em zonas urbanas centrais com prédios imponentes, o aumento da demanda por escolas criou situação de expansão dos novos grupos escolares nos subúrbios e periferias urbanas em condições infraestruturais adversas, como no caso do Grupo Escolar Cônego Ângelo e de muitos outros no Pontal Mineiro. Dessa forma, o contexto teria levado a um retorno aos pardieiros agora instalados sob a designação grupos escolares nas periferias urbanas? A quem interessava a ampliação da rede pública de ensino precária em variados aspectos naquele contexto?

O grupo escolar aqui analisado foi criado na cidade de Ituiutaba-MG em outubro de 1963, momento em que o município atravessava acelerado crescimento urbano. Percebe-se pela tabela que é na década de 1960 que ocorre a inversão entre população rural e urbana nesse município, expressando o que ocorria também em nível de país de forma que a maior parte dos indivíduos passou a viver nas cidades brasileiras em busca de melhores condições de vida (saúde, moradia e educação) e com perspectiva de empregabilidade no comércio e setor de serviços públicos que se expandiam com velocidade.

Tabela 01 - População Rural e Urbana do Município de Ituiutaba

\begin{tabular}{|c|c|c|c|c|c|}
\hline ANO & População Rural & \% & População Urbana & \% & Totais \\
\hline 1940 & 30.696 & $88 \%$ & 4.356 & $12 \%$ & 35.052 \\
\hline 1950 & 43.127 & $81 \%$ & 10.113 & $19 \%$ & 53.240 \\
\hline 1960 & 39.488 & $55 \%$ & 31.516 & $45 \%$ & 71.004 \\
\hline 1970 & 17.542 & $27 \%$ & 47.114 & $73 \%$ & $64.656^{2}$ \\
\hline
\end{tabular}

Fonte: SOUZA, 2010, p.527. 
A grande movimentação na economia de Ituiutaba encontrava paralelo na política de modernização nacional, que forçaria uma expansão no sistema público de ensino. É nesse contexto que se criou e se implantou o Grupo Escolar Cônego Ângelo, período marcado pela intervenção dos militares na política, e sua inserção nos altos cargos na administração pública e privada, resultando no controle exacerbado de direitos civis e políticos da sociedade brasileira. Foram elaborados pelos presidentes militares os instrumentos legais de repressão, os conhecidos atos institucionais, que lhes davam subsídios legais para reprimir as vozes destoantes, como movimentos sociais e oposicionistas. Assim, o estado brasileiro que no início da década de 1960 assumia um papel de atender determinados interesses das classes populares, colocou-se quase integralmente na posição de mediador dos anseios das empresas privadas nacionais e multinacionais no pós- $64^{3}$, de maneira que a população teve direitos restringidos, principalmente na política e na economia.

É neste âmbito que foram realizados vários acordos entre Ministério da Educação e Cultura (MEC) e United States Agency for International Development (USAID), estes cobriram todo o espectro da educação nacional, isto é, o ensino primário, médio e superior, a articulação entre os diversos níveis, o treinamento de professores e a produção de livros didáticos. O resultado foi o controle do sistema educacional na tentativa de se divulgar nova ideologia ${ }^{4}$, treinar número de pessoas suficiente para o mercado de trabalho, gerando uma visão positiva do capital e da competição, adotando-se uma teoria educacional com influência americana onde se deveria privilegiar a tecnocracia e o economicismo (FREITAG, 2005).

Esses acordos foram traduzidos em mudanças na legislação educacional que modificaram todos os níveis do ensino, destacam-se a Reforma Universitária (1968) e a lei $n^{\circ} 5692 / 71$ que reformava a LDB 4024/61, essa nova lei buscou promover a habilitação profissional para atender a demanda por mão de obra qualificada.

Com a profissionalização universal e compulsória, os estudantes já sairiam do $2^{\circ}$ grau com uma habilitação profissional e procurariam logo um emprego, o que não seria difícil, já que o "milagre econômico" prometia empregos e salários crescentes. (CUNHA; GÓES, 1985, p.66)

As universidades foram um dos principais alvos da repressão militar já que os universitários representavam o maior foco de resistência ao regime. Medidas administrativas buscavam desestruturar a coesão do movimento estudantil, de maneira que criavam turmas com excesso de alunos, buscando-se a chamada racionalização dos recursos, diminuindo-se os gastos com os salários de professores, resultando em perdas na aprendizagem e sobrecarga de trabalho docente o que os levava muitas vezes a um imobilismo político. Dessa forma o ensino universitário se reestruturou com modelo seletivo nas universidades públicas e mais tolerante/flexível nas universidades privadas. Os cursos mais baratos como exemplo, as licenciaturas, proliferaram-se nas instituições particulares, enquanto os mais caros permaneceram nas universidades públicas.

A reação das classes dirigentes e dos seus aliados internacionais, de amplos setores das classes médias e das Forças Armadas redundou na deposição de Jango e na implantação de um regime político de cunho ditatorial cuja principal preocupação era estancar as mobilizações sociais. É claro que a repressão atingiu duramente o campo educacional, em especial, a educação popular como os movimentos inspirados na teoria freireana (PAIVA, 1987). A resposta da ditadura para a questão da alfabetização de adultos foi a instituição do Movimento Brasileiro de Alfabetização (MOBRAL), criado no ano de 
1967 pela lei $\mathrm{n}^{\circ}$ 5.379, tal programa representou um dos maiores fenômenos da propaganda ditatorial.

O MOBRAL não hesitou em utilizar, extraindo-as de seu contexto filosófico e político, as técnicas de alfabetização de Paulo Freire. Podemos dizer que o método foi refuncionalizado como prática, não de liberdade, mas de integração ao "Modelo Brasileiro" ao nível das três instancias: infraestrutura, sociedade política e sociedade civil. (FREITAG, 2005, p.159).

Dessa maneira, os grupos escolares criados nesse período foram atravessados pelas propostas do regime político instalado em 1964 e deveriam, sobretudo, prover os rudimentos da escrita e da leitura junto as massas que se adensavam nas zonas urbanas.

Analisando o processo de expansão das instituições educacionais na cidade de Ituiutaba (polo administrativo do Pontal Mineiro) evidencia-se acelerado movimento de criação dos grupos escolares na sede do município. Fica claro que os anos de 1950 e 1960 representam momento de interseção no campo educativo, já que os governos tanto civis quanto militares empenharam-se na inserção da grande massa da população na rede pública escolar, atendendo aos filhos das classes populares. Pela tabela 02, constata-se que na década de 1960 o número de grupos escolares dobrou na sede do município.

Tabela 02 - Ano de criação das escolas públicas na cidade de Ituiutaba ${ }^{5}$

\begin{tabular}{|l|c|l|c|}
\hline \multicolumn{1}{|c|}{ ESCOLAS ESTADUAIS } & ANO & \multicolumn{1}{|c|}{ ESCOLAS MUNICIPAIS } & ANO \\
\hline GE João Pinheiro & 1908 & EM Machado de Assis & 1941 \\
\hline GE Prof.Idelfonso Mascarenhas & 1947 & EM Francisco Antônio de Lorena & 1951 \\
\hline GE Sen. Camilo Chaves & 1955 & EM Manoel Alves Vilela & 1966 \\
\hline GE Clóvis Salgado & 1956 & EM Agrícola de Ituiutaba & 1970 \\
\hline GE Rotary & 1956 & Cime Mun. Tancredo P. Almeida & 1971 \\
\hline GE Arthur Junqueira de Almeida & 1958 & EM Pref. Camilo Chaves Junior & 1979 \\
\hline GE Gov. Bias Fortes & 1959 & EM Rosa Tahan & 1980 \\
\hline GE Cel. João Martins & 1960 & EM Aida de Andrade Chaves & 1982 \\
\hline GE Cônego Angelo & 1963 & Cime Sarah Feres de Silveira & 1989 \\
\hline GE Gov. Israel Pinheiro & 1965 & EM Nadime Derze Jorge & 1992 \\
\hline GE Antonio Souza Martins & 1965 & EM Aureliano Joaquim da Silva & 1996 \\
\hline GE Cel. Tonico Franco & 1965 & EM Hugo de Oliveira Carvalho & 1999 \\
\hline GE Dr. Fernando Alexandre & 1965 & EM Clorinda Junqueira & 2007 \\
\hline Dr. José Zocolli de Andrade & 1965 & & \\
\hline $\begin{array}{l}\text { GE Prof. Álvaro Brandão de } \\
\text { Andrade }\end{array}$ & 1968 & & \\
\hline EE Profa Maria de Barros & 1974 & & \\
\hline EE Educ. Esp. Bem Me Quer & 1986 & & \\
\hline Cesec Clorinda M Tavares & 1987 & & \\
\hline
\end{tabular}

Fonte: SOUZA, 2010, p. 528.

Entre as décadas de 1950 e 1960, a legislação vigente colocava a expansão das escolas sob responsabilidade do governo estadual, de forma que em vinte anos, esse número de escolas passaria de apenas 02 para 15, mantidas pelo estado de Minas Gerais. $\mathrm{O}$ poder municipal criou outras 03 escolas, além das 04 instituições que eram geridas por organizações filantrópicas (SOUZA, 2010). 


\section{A Implantação do Grupo Escolar Cônego Ângelo}

A proposta em estudar o processo de implantação do Grupo Escolar Cônego Ângelo decorreu do fato de ter sido uma escola voltada para a escolarização das classes populares que habitavam a periferia do município, portanto, um objeto marginal na historiografia da educação brasileira, cuja história foi marcada por precariedade e desafios superados para que pudesse existir enquanto instituição escolar com identidade própria. Tal marginalidade fica evidenciada também pela invisibilidade dessa instituição na imprensa local.

Essa escola foi criada no dia 10 de outubro de 1963, no entanto, o grupo escolar foi oficializado e inaugurado apenas no dia 28 de novembro de 1964, por meio da autorização do governador do estado de Minas Gerais, José de Magalhães Pinto, que promulgara o decreto $\mathrm{n}^{\mathrm{o}} 7215$, designando a instituição como Grupo Escolar Padre Cônego Ângelo Tardio Bruno ${ }^{6}$, homenagem a um personagem importante em vários episódios no desenvolvimento da cidade e da região.

Ao analisarmos a trajetória dessa instituição, buscamos enfrentar a questão da identidade construída ao longo de seu desenvolvimento, de maneira que como metodologia de trabalho, elegemos algumas categorias para estudo quais sejam a arquitetura escolar, os sujeitos (perfil de alunos, professores e gestores), as práticas pedagógicas e por fim, considerações sobre o cotidiano dessa escola. O então recém criado grupo escolar ficaria quase duas décadas sem sede própria, de maneira que a precariedade de suas instalações, desde o início representou uma expressão de luta para a comunidade escolar que não contava com outra possibilidade para a escolarização das crianças das classes populares, assim, professores, diretores e pais de alunos reivindicavam melhorias e promoviam ações visando manter a escola em funcionamento.

O espaço físico do grupo escolar. Em seu início a escola foi organizada em quatro setores distantes da cidade, com salas de aulas separadas em virtude do número elevado de alunos em cada série (a escola recebeu quase 400 matrículas no ano inicial em 11 salas de aula). Assim, havia salas no setor denominado "Pedreira" (sul do município), onde os discentes assistiam as aulas em prédio metálico (pré-fabricado), outras salas na rua 34 entre as avenidas 23 e 25 (no alto da cidade), no bairro Platina na Avenida 17, e na capela de Nossa Senhora da Aparecida no Bairro Natal. No ano de sua criação, essa escola atendia de $1^{\circ}$ a $4^{\circ}$ série, contava com 26 funcionários. A maior demanda de alunos localizava-se no bairro periférico Natal (onde posteriormente fora construída a sede própria), por este motivo, em 1967, a escola passaria a funcionar somente nas dependências cedidas pela igreja.

Pelas imagens e depoimentos da época é possível avaliar os desafios e as limitações dos alunos e professores, que desde seu início enfrentaram, falta de espaços básicos como sanitários e refeitórios, sem falar na ausência quase que total de materiais didáticos adequados ao trabalho cotidiano de funcionários, professores e alunos. Essas condições precárias dos grupos escolares criados nos anos de 1950 e 1960 eram frequentemente denunciadas pelos jornais locais, no entanto,

(...) tais críticas eram feitas com bastante cautela. Os problemas dessa expansão precária dificilmente apareciam na imprensa associados a alguma figura política específica, mas a responsabilidade era de certa forma despersonalizada, e a redação das matérias limitava-se quase 
sempre a fazer apelo às autoridades ora locais, ora estaduais. (SOUZA, 2010, p.536)

Mesmo que a partir de 1967, a escola passou a se localizar em apenas um prédio, sua estrutura permanecia limitada, de maneira que foi feita a ampliação deste local, com o auxilio de instituições religiosas e campanhas realizadas por professores e funcionários. Assim, foram construídas mais duas salas de aulas, quatros sanitários e um bebedouro, adaptando-se as instalações a partir das necessidades encontradas. A imagem que segue mostra o imóvel onde as atividades eram desenvolvidas em fins da década de 1960.

\section{Figura 01 - Fachada do Grupo Escolar Cônego Ângelo (1967)}

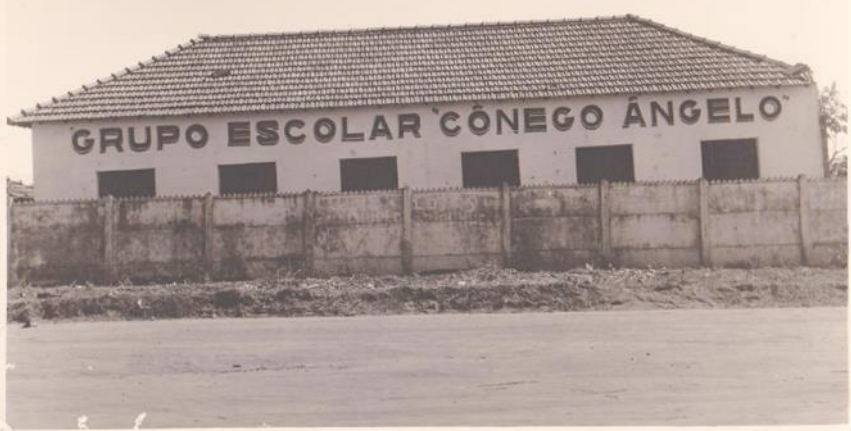

Fonte: Acervo da Escola Estadual Cônego Ângelo (2013).

Pelos depoimentos colhidos, a comunidade escolar se referia ao prédio desse grupo escolar como "casarão", as salas eram dividas por biombos de madeira que permitiam a divisão de acordo com a demanda das séries em que os alunos se matriculavam, a sala dos professores era improvisada, não havia espaço adequado para os alunos lancharem e nem quadra para a prática da educação física. Essas dificuldades são relatadas pela ex-diretora Ana Martins (nome fictício) ${ }^{7}$ (2013):

Tinha sala de professores porque você sempre tirava um canto e falava aqui é a sala dos professores, punha umas três cadeiras lá servia numa mesa grande um cafezinho, cada dia uma levava um lanche, cada dia uma levava um bolo. Outro dia pegamos dinheiro emprestado. Eu me lembro que naquela época era Cr\$500,00 pra comprar uma caçarola grandona de fazer sopa. Aí, os pais sempre foram muito grandes colaboradores, então juntaram um tanto de pedra lá, botaram essa panela e pôs pra cozinhar, e foi a primeira sopa servida feita em quatro pedras e essa caçarola. Não existia fogão e cada menino levava seu copo então lá foi o primeiro lanche.

Tal depoimento evidencia que a implantação da escola pública na cidade trouxe desafios e portou contradições em vários aspectos, a começar pelos espaços de trabalhos. Em decorrência disso, a escola se organizou com auxílio da Igreja Católica, da Associação das Senhoras Voluntárias e campanhas realizadas pelas professoras por meio de rifas e da adoção do "Livro de Ouro" (doações) em prol da escola, o que permitiu adaptar uma casa 
vizinha como cantina e novas salas de aula. Tais condições de existência fizeram com que a luta pelo prédio próprio fosse permanente desde o início junto à comunidade escolar, contudo nem sempre as reivindicações tinham ressonavam na classe política, vejamos:

Lutamos sempre pedindo o prédio, a gente nessa luta sempre pedindo aos políticos, a gente telefonava às vezes não era muito bem recebido, uma vez fui cumprimentar o prefeito e ele não me deu a mão. [...] Ai eu fiquei muito mal e muito desapontada (MARTINS, 2013).

As reivindicações de gestores e professores não cessariam ao longo de toda a década de 1970, até a aprovação do início da construção do almejado prédio próprio, assim, em 18 de agosto de 1982, foi inaugurado a sede da então Escola Estadual Cônego Ângelo (outrora grupo escolar) pelo Governo Francelino Pereira, que autorizou a mudança para as novas instalações, conforme ofício n ${ }^{\circ} 1781 / 82$.

A primeira etapa de existência da escola fora ultrapassada com a efetivação de infraestrutura ampla contendo horta escolar, salas de aula apropriadas, espaço para biblioteca, sala de professores e uma cantina com espaço para os alunos se alimentarem. Em 1985, de acordo com a resolução 5276/85, houve a extensão do ensino da escola para a $5^{\mathrm{a}}$ série (ensino fundamental).

Sujeitos da história: perfil de Alunos, Professores e Gestores. No percurso da pesquisa, localizamos quatro ex-alunas da escola, sendo Salete Moraes, Gilsa Moura, Marina Silva e Elita Castro (nomes fictícios). Todas estudaram no prédio cedido pela Igreja Católica, portanto, na fase inicial da instituição. Salete Moraes ${ }^{8}$ relata que trabalhava na casa de família como doméstica na parte da manhã e a tarde estudava no Grupo Escolar Cônego Ângelo, para ajudar na renda familiar, na idade adulta cursou o magistério. Assim relatou a rotina dessa escola.

Lembro-me da diretora era a Dona Ana, e ela tinha um relacionamento muito bom com os alunos, na hora do recreio ela estava no pátio, assim os alunos a respeitavam, e ela sempre assim (...) amiga dos alunos. Eu era muito tímida, eu não era muito próxima do professor não! Eu era mais no meu canto, eu me soltava mais na hora do recreio, mas dentro de sala não, só que era assim, eu era tímida, mas não tinha dificuldades não! Eu acompanhava normalmente a aula. Tinham os castigos, né!? A forma de punição era o castigo. Eu lembro assim, se fizesse alguma coisa ficava em pé lá na sala, a professora usava essas estratégias, assim (...) com muitos alunos. (MORAES, 2012)

O relato demonstra que apesar das modificações proclamadas pela Escola Nova a partir da primeira república, a educação tradicional se mantinha com base na autoridade das figuras do diretor e do professor. Também a ex-aluna Gilsa Moura ${ }^{9}$ teve sua trajetória escolar permeada por desafios, desde o primeiro ano de estudos encontrou dificuldades, e foi reprovada na primeira série, depois seguiu seus estudos normalmente e concluiu a quarta série no grupo escolar. Segundo suas memórias sobre a rotina da escola, afirma que as professoras organizavam suas atividades avaliativas em forma de provas mensais e bimestrais, cadernos e arguições, ela considera que "não atingia o conhecimento necessário, mas você tinha que demonstrar que sabia. Era questão de memorização, não tinha essa questão de metas a serem atingidas e que a culpa era dos professores. Quanto mais se reprovava melhor seria" (MOURA, 2013). Mais tarde Gilsa, tornara-se professora 
da mesma escola onde estudou, concluiu o nível superior e o mestrado em educação. De acordo com Saviani (1991, p.18), tal prática expressava a pedagogia tradicional, apoiada sobre o saber docente:

O essencial era contar com um professor razoavelmente bem preparado. Assim, as escolas eram organizadas em forma de classes, cada uma contando com um professor que expunha as lições que os alunos seguiam atentamente e aplicava os exercícios que os alunos deveriam realizar disciplinadamente.

Por meio desses depoimentos, revela-se que as práticas tradicionais ainda predominavam no modelo republicano de escola, onde o aluno seria o receptor do conhecimento, cuja didática máxima era a memorização. A reprovação da depoente era uma realidade bastante presente nesse período, realidade de muitas famílias que tinham a sua primeira geração inserida na escola, mas o que muitas vezes determinava o sucesso ou fracasso na escola era a condição social que impulsionava as crianças precocemente ao mercado de trabalho, de forma que um dos maiores problemas do Grupo Escolar Cônego Ângelo era a evasão/reprovação. Vejamos:

Tabela 03 - Alunos Aprovados e Reprovados por ano/série

\begin{tabular}{|c|c|c|c|c|c|c|c|c|c|c|c|}
\hline \multirow[t]{2}{*}{ Ano } & \multicolumn{2}{|c|}{$1^{\circ}$ serie } & \multicolumn{2}{|c|}{$2^{\circ}$ serie } & \multicolumn{2}{|c|}{$3^{\circ}$ serie } & \multicolumn{2}{|c|}{$4^{\circ}$ serie } & \multicolumn{2}{|c|}{$\begin{array}{l}\text { Total } \\
\text { Geral }\end{array}$} & \multirow{2}{*}{$\begin{array}{c}\text { Total } \\
\text { de } \\
\text { salas }\end{array}$} \\
\hline & Apr & Rep & Apr & Rep & Apr & Rep & Apr & Rep & Apr & Rep & \\
\hline 1964 & 315 & 76 & $*$ & $*$ & * & $*$ & $*$ & $*$ & 315 & 76 & 11 \\
\hline 1965 & 366 & 45 & $*$ & * & $*$ & $*$ & $*$ & $*$ & 366 & 45 & 14 \\
\hline 1966 & 231 & 115 & $*$ & $*$ & $*$ & $*$ & $*$ & $*$ & 231 & 115 & 12 \\
\hline 1967 & 94 & 20 & $*$ & $*$ & $*$ & $*$ & $*$ & $*$ & 94 & 20 & 4 \\
\hline 1968 & $*$ & $*$ & $*$ & $*$ & $*$ & $*$ & $*$ & $*$ & $*$ & $*$ & $*$ \\
\hline 1969 & 239 & 67 & 100 & 15 & 68 & 20 & 28 & 6 & 435 & 108 & 19 \\
\hline 1970 & 96 & 28 & 121 & 7 & 87 & 9 & 50 & 7 & 354 & 51 & 18 \\
\hline 1971 & 106 & 00 & 99 & 12 & $*$ & $*$ & 65 & 2 & 270 & 14 & 16 \\
\hline 1972 & 141 & 09 & 99 & 18 & * & $*$ & 59 & 2 & 299 & 29 & 15 \\
\hline 1973 & 238 & 151 & 107 & 17 & 49 & 24 & 59 & 00 & 453 & 192 & 21 \\
\hline 1974 & 56 & 127 & 108 & 96 & 58 & 40 & 58 & 4 & 280 & 267 & 16 \\
\hline 1975 & 182 & 143 & 138 & 105 & 66 & 43 & 63 & 19 & 449 & 310 & 20 \\
\hline 1976 & 140 & 167 & 171 & 92 & 69 & 67 & 75 & 25 & 455 & 351 & 20 \\
\hline 1977 & 154 & 190 & 178 & 118 & 60 & 45 & 64 & 37 & 456 & 390 & 22 \\
\hline 1978 & 178 & 198 & 171 & 74 & 101 & 70 & 72 & 28 & 522 & 370 & 24 \\
\hline 1979 & 172 & 186 & 206 & 106 & 117 & 78 & 115 & 29 & 610 & 399 & 24 \\
\hline 1980 & 140 & 140 & 191 & 128 & 113 & 61 & 107 & 33 & 551 & 362 & 23 \\
\hline 1981 & 104 & 163 & 165 & 115 & 156 & 107 & 122 & 93 & 547 & 478 & 22 \\
\hline 1982 & 197 & 160 & 56 & 35 & 106 & 81 & 144 & 131 & 503 & 407 & 26 \\
\hline 1983 & 228 & 150 & $*$ & $*$ & 190 & 53 & 141 & 80 & 559 & 283 & 20 \\
\hline 1984 & 227 & 176 & $*$ & $*$ & 162 & 48 & 164 & 87 & 553 & 311 & 19 \\
\hline 1985 & 174 & 152 & $*$ & $*$ & 138 & 67 & 142 & 98 & 454 & 317 & 18 \\
\hline
\end{tabular}

Fonte: Acervo da escola, cadernos de promoções dos alunos das séries $1^{\circ}, 2^{\circ}, 3^{\circ}, 4^{\circ}(1964-$ 1985). 
Pela tabela é possível refletir sobre o desempenho do corpo discente da escola: em primeiro lugar, como já afirmamos, fica demonstrado o alto índice de reprovação que em alguns momentos chegavam a quase $50 \%$ dos alunos matriculados especialmente ao longo dos anos de 1970, momento em que o setor agrícola da região viveu crise de produção; em segundo lugar, observa-se que o acelerado processo de urbanização do município forçava a ampliação desordenada da rede escolar e essa instituição é exemplo disso, logo em seu primeiro ano já matriculava quase quatro centenas de alunos apenas na $1^{\mathrm{a}}$ série, de forma que o número de matrículas foi crescendo continuamente até quase um milhar; por último, a tabela mostra o afunilado sistema de ensino, já que o maior número de alunos se concentrava na primeira série, muitos não seguiam os estudos depois de seguidos fracassos na instituição escolar na etapa de alfabetização.

A condição social instável de muitos dos alunos da escola foi evidenciada também pelos relatos de ex-professores e ex-gestores. Entrevistamos três docentes e a primeira diretora da escola, com exceção da professora Margarida Soares (nome fictício), as outras tiveram trajetórias parecidas, deixaram suas famílias nas fazendas e se mudaram para a cidade com o objetivo de concluir os estudos. Quanto à formação, todas elas cursaram o magistério e depois a graduação em Pedagogia, mas desde cedo conseguiram emprego na área da educação. Sendo a maioria filhas de proprietários rurais.

De acordo com os relatos, havia um processo de seleção de professores para trabalharem na escola, a chamada designação. Os professores eram avaliados pelos gestores que segundo Alves (2013) só era possível conseguir uma vaga quando "a diretora topava com sua cara te arrumava serviço". Portanto, podemos perceber que a contratação tinha critérios bastante subjetivos quando não eram políticos já que também havia a indicação de amigos ou parentes das lideranças políticas (o apadrinhamento), assim, a formação no campo não era um critério prioritário.

Essa política de contratação era também realidade junto aos gestores, conforme relato da ex-diretora do grupo escolar, afirmando que assumiu o cargo de direção por meio de indicação política, representando um cargo estratégico para políticos, segundo a gestora se alguém da família fosse político contrário ao partido vencedor "na hora eles destituíam a moça” (MARTINS, 2013). Nesta fala fica explícita a velha prática do compadrio. diretoras:

No período aqui analisado, o Grupo Escolar Cônego Ângelo contou com três

Tabela 04 - Relação de Gestores (1963-1985)

\begin{tabular}{|c|c|}
\hline DIRETORAS & PERÍODO DE ATUAÇÃO \\
\hline Célia Tomaz & 1963 a 1966 \\
\hline Ana Martins & 1966 a 1984 \\
\hline Dalva Guimarães & 1984 \\
\hline
\end{tabular}

Fonte: Arquivo da escola. Caderno de Registros (nomes fictícios).

Como se vê, a gestora Ana Martins atuou na escola por dezoito anos, de acordo com seu depoimento, as razões para esta longa permanência decorreu da dedicação a consolidação da escola que segundo a ex-gestora "Vivia em prol do grupo escolar" (MARTINS, 2013). Neste sentido o seu papel era ampliado abrangendo o pedagógico, o administrativo e para as demais necessidades da escola, como a merenda, por exemplo.

No que concerne ao trabalho docente, às condições de trabalho eram precárias não tendo muitas vezes o pagamento de seus salários, "o governo pagava o professor quando 
achava por bem e como achava que podia" (MARTINS, 2013). Deste modo, percebe-se o descaso com a educação, principalmente destinada às séries iniciais para as crianças das classes populares, a massificação da escola foi feita transferindo-se responsabilidades a sociedade civil, conforme apontado por Germano (2005) sobre a educação pública na Ditadura.

Em todas as entrevistas as dificuldades de trabalho são presentes, especialmente em relação aos materiais didáticos, a professora Soares (2013) afirmou "agente comprava material e trocava umas com as outras". Outras dificuldades relatadas pelas entrevistadas, conforme já adiantamos era o público atendido, originados na classe trabalhadora, já que em muitos casos, os alunos não tinham contato com leituras e nem mesmo "sabiam pegar no lápis", assim, o esforço girava em torno da alfabetização, como no relato da exprofessora.

A maioria dos alunos vinha da fazenda. Crianças que nunca tinham pego no lápis. Então era essa a clientela de lá. Eu, sempre gostava daqueles meninos que nunca tinham ido na escola. Que a gente pegava na mãozinha para poder ensinar a primeira letrinha (SOARES, 2013).

Neste sentido a gestão adotava estratégias para manter os alunos frequentes, não só propiciando a aprendizagem, mas oferecendo aos alunos merenda em horários diferenciados e propondo encontros com as famílias na escola, com o objetivo de mudar a realidade, conforme relata Soares (2013):

Era uma luta, todo mundo trabalhava, e eu sofria porque eu achava um crime meus alunos de noite, aqueles meninos de 10, 12 anos, 13 as vezes, os grandinhos eram de 13 e 15 anos, dormindo nas carteiras, suados sem janta. Aquilo eu morria do coração, ai comecei a dar em cima pra esse povo não dar emprego pra eles, mas se não davam emprego faltava o pão porque em casa eles tinham que dar uma ajudinha.

Diante disso, ressaltamos que boa parte dos grupos escolares criados nesse período enfrentaram as mesmas condições precárias em seu início, além de enfrentarem as dificuldades relativas à condição social da comunidade que frequentavam essas escolas.

Práticas Pedagógicas e Avaliativas. O trabalho pedagógico desenvolvido nesse Grupo Escolar inspirava-se em métodos tradicionais, tornando o professor à figura central e aos alunos caberia um papel de figuração no processo de ensino e aprendizagem, de forma que os professores eram ainda uma fonte inquestionável de conhecimento. Segundo a aluna Elita Castro (2013).

Se você olhasse pra trás tomava uma reguada. Na verdade o professor, ele sempre foi visto como uma pessoa superior e um "sabe tudo". Naquela época a gente olhava para o professor e pensava isso, né?! O professor, ele danava, ele tinha um respeito, todo mundo olhava. Assim as pessoas tinham mais receio com os professores em sala de aula.

Esse tipo de prática resultava em punições aos alunos que ferissem as normas, segundo relato das entrevistadas o castigo mais comum era a impossibilidade de sair para o recreio, como lembra a aluna Marina Silva (2012), filha de trabalhadores rurais que estudou no grupo escolar e posteriormente formou-se em pedagogia. 
Sabe a cartilha e aquelas lições. A dona Rosa na época, eu lembro que, quem não dava conta, (...) por exemplo, quando ela passava uma lição pra casa para ela tomar no outro dia se a gente não desse conta, a gente ficava na hora do recreio estudando retomando aquela lição que a gente não aprendeu.

Nessa lógica, a prática pedagógica e avaliativa exercida no grupo escolar contribuiu para uma aprendizagem baseada na memorização e reprodução o que atendia aos preceitos do governo ditatorial. O depoimento de Castro (2013) também revela isso: "que rosa era vermelha, você não podia pintar rosa de azul", ou seja, castrava-se a criatividade infantil. Como falamos, a cartilha era o único material didático trabalhado, muito embora, havia a indicação no planejamento inicial de conteúdos e didática para cada série.

\section{Figura 5 - Caderno de termo de abertura (1970)}

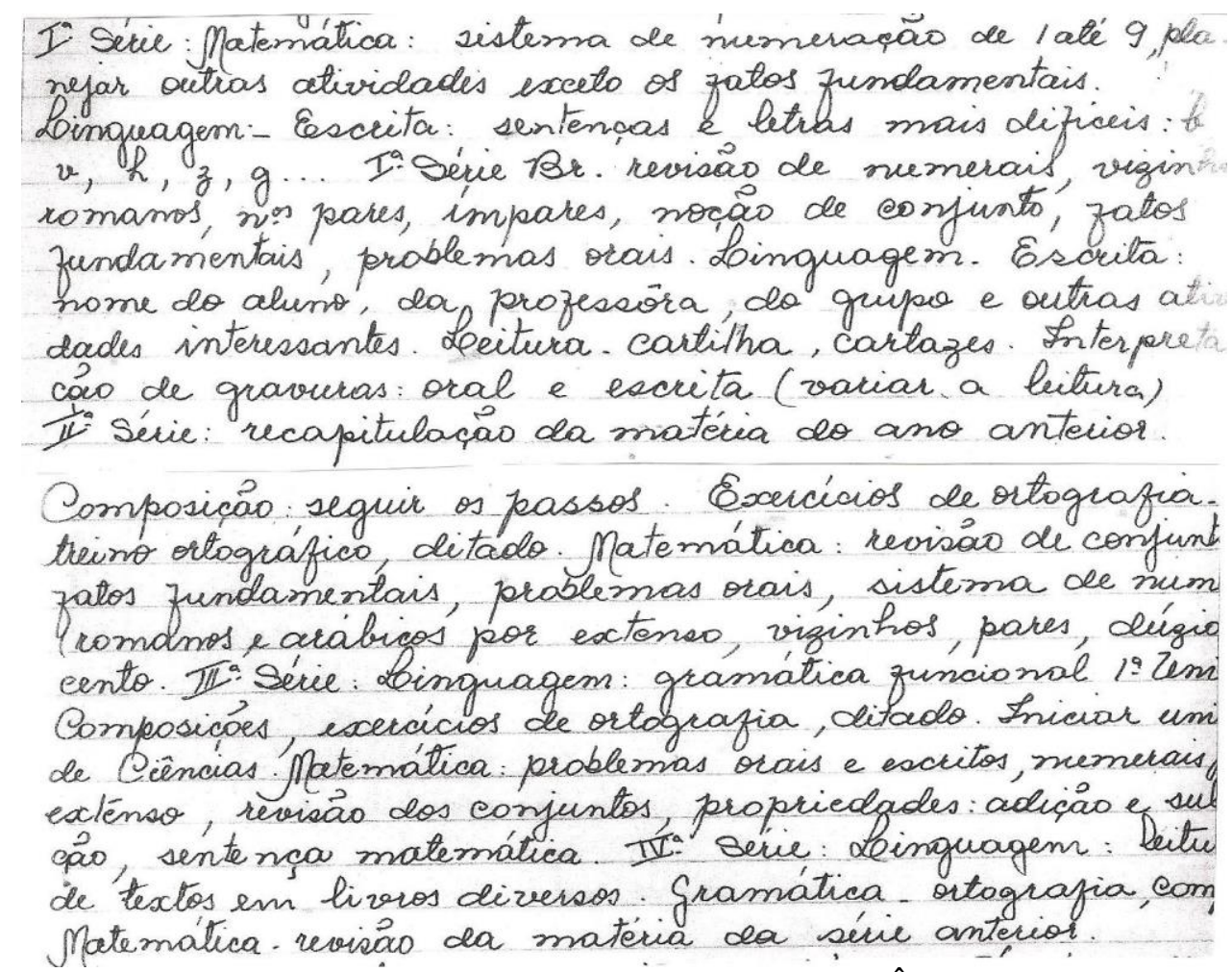

Fonte: Acervo: Grupos Escolar Cônego Ângelo

Constata-se que o grupo escolar tinha uma preocupação acentuada com a alfabetização (rudimentos da leitura e da escrita), além das operações matemáticas básicas. Em relação ao nível de desenvolvimento dos alunos, era disponibilizada aos professores uma ficha de observação, com perguntas a serem respondidas em todos os bimestres. Esta ficha contemplava o desenvolvimento afetivo, cognitivo e psicomotor, e a partir dela o professor apresentava condições para avaliar o desenvolvimento do aluno, segundo a exgestora Ana Martins (2013) "com esses dados o Grupo Escolar Cônego Ângelo e os pais acompanhavam o desenvolvimento de seus filhos".

A escola contou com projetos de aceleração, de acordo com a professora Margarida Soares "eles saiam sabendo ler e escrever corretamente. Foi um projeto que teve, chamava 
projeto ALFA, era através de som. Dentro de um mês, o menino estava, que você precisa ver que gracinha". De acordo com Bernardes (2002) este programa foi desenvolvido em diversos estados do Brasil na década de 1970, com a finalidade de diminuir o fracasso escolar e abrandar o número de reprovações na $1^{\text {a }}$ série que hoje é o primeiro ano fundamental. No entanto, este programa era destinado às crianças de classes populares, com a finalidade de acelerar os estudos destes alunos.

Por fim compreendemos que as práticas dos docentes continuavam sob a perspectiva tradicional, como já citado neste trabalho. O professor continuava como a figura onipresente, detentor dos conhecimentos. As avaliações não consideravam um conhecimento construído pelo aluno, mas apenas a memorização dos exercícios. Contudo, essa inserção na escola representou a oportunidade de escolarização de parte dos filhos das classes populares que até então, estavam excluídas do sistema escolar, porém, o grande número de reprovações já na $1^{\circ}$ série levava muitos a evasão não seguindo seus estudos, o que reforçava o fosso social.

Notas sobre o cotidiano do grupo escolar. A vida cotidiana desse grupo escolar seguia uma rotina, as aulas se iniciavam às sete horas da manhã e se encerravam até as onze e meia, no segundo turno as aulas iniciavam ao meio dia tendo a duração ate as quatro e meia da tarde. Na medida em que a escola se organizou, todas as manhãs era servido um lanche, que segundo a ex-gestora se compunha de leite ou mingau, em função da grande quantidade de alunos que não se alimentava em suas casas, caso contrário tinham que aguardar o intervalo para fazer a primeira refeição do dia. Ressaltamos que as refeições servidas, em boa parte do período estudado, vinham de parceria entre escola, comerciantes e da Associação das Senhoras Voluntárias Consagradas na Igreja Católica. Segundo o seu depoimento os alimentos recebidos com mais frequência eram ossos, muxibas, costelas e arroz quebrado doados pelas casas de carnes e pelos proprietários de máquinas de beneficiamento de arroz.

Era um lanche muito simples. Muito diferente de hoje. Uma sopinha. Para você ter uma ideia a macarronada era para dia de festa da escola. Era escaldado, pão, mingau, o pão com recheio era para a semana do dia das crianças porque era quando o lanche dava uma melhorada. (MOURA, 2013).

Diariamente, era organizado um encontro no pátio da escola, as crianças se reuniam no galpão em fila, para realizar uma oração e cantar músicas religiosas. E uma vez por semana era realizado o momento cívico, ao final, os alunos se dirigiam para as salas de aula sempre em fila conduzidos pelos professores.

A gente fazia o horário cívico, nós tínhamos assim todos os dias tinha aquela rotina agente chegava, as salas estavam fechada, a gente ia para $o$ pátio todo dia antes de ir para a sala de aula tinha o momento de oração. Mas o momento cívico de hino nacional (...) acho que era uma vez por semana. (MORAES, 2012)

Embora os entrevistados não tenham se referido diretamente, compreendemos que neste período era finalidade do governo ditatorial inserir nas escolas a Educação Moral e Cívica, que representava uma sólida fusão do pensamento reacionário, do catolicismo conservador e da doutrina da segurança nacional, conforme era concebida pela Escola 
Superior da Guerra. É interessante notarmos a presença constante da Igreja Católica no cotidiano desse grupo escolar, com a presença do padre dando início as festividades que reuniam a comunidade escolar. (CUNHA; GÓES, 1985)

Entre as festas realizadas no ambiente do Grupo Escolar, destacam-se as formaturas da quarta série que eram entregues os certificados aos alunos, e a participação nos desfiles, muito embora poucos alunos participavam segundo relata a ex-aluna Gilsa sobre a festividade do dia 7 de setembro "Mas tinha um problema, a maioria dos alunos não podiam desfilar, por conta de não ter um tênis, sapato e uniforme. Eu mesma nunca desfilei". Este era apenas mais um dos problemas enfrentados pelas escolas populares surgidas nesse período, muitas vezes, as famílias sequer tinham condições de comprar uniformes para os seus filhos.

\section{Considerações Finais}

Certamente esta pesquisa não esgota as diversas leituras que ainda podem ser levantadas sobre o Grupo Escolar Cônego Ângelo. Todavia os estudos acadêmicos sobre tais instituições nesse período da história brasileira podem revelar muito mais, pois existem fatos peculiares a cada escola que extrapolam as generalizações frequentemente promovidas em variadas pesquisas que enfocam a história da macro política no campo educativo.

Nessa perspectiva, os resultados mostraram que esse grupo escolar (com a lei $5692 / 71$ passou a ser escola estadual) foi criado sem nenhum planejamento infraestrutural o que gerou dificuldades aos gestores, docentes e discentes, não tendo espaço adequado e próprio por muitos anos. Contudo, representou ao mesmo tempo, a oportunidade de escolarização dos filhos das classes populares que até então, estavam excluídas do sistema escolar, muito embora, o fracasso escolar foi o que muitos encontraram.

Desde os anos de 1950, acentuou-se a crença na educação redentora de maneira que setores da sociedade civil se lançaram na empreitada civilizatória com o intuito de educar os pobres, misturando-se patriotismo, religião e família, reforçando-se os valores mais caros a nação. Os grupos escolares criados a partir dos fins da década de 1940, na cidade de Ituiutaba-MG tinham a mesma proposta de educação das classes populares. Contudo, a precariedade de seus processos de implantação foi marca comum a vários deles, distinguindo-se dos "Palácios Escolares" (FARIA FILHO, 2000) do início da República, assim, muitos deles tiveram seu início muito mais parecido com os velhos "pardieiros" ou escolas isoladas. Por isso mesmo, ao longo da década de 1970, a partir da promulgação da lei 5692/71, teve inicio uma reorganização das redes públicas de ensino e se extinguiu a designação "grupo escolar", já que não mais representava a forma autorizada ou o símbolo da modernidade republicana, como no inicio do século XX.

Enfim, por meio de breve estudo dos perfis dos alunos, professores, gestores, cotidiano escolar, infraestrutura e práticas pedagógicas foi possível resgatar as origens de criação de uma escola destinada as classes populares, ampliando o conhecimento da história da educação da cidade de Ituiutaba. Assim, acreditamos ter contemplado a proposta desse trabalho, ou seja, a valorização de uma história pouco registrada e de nenhum glamour, o que destoa da trajetória de escolas tradicionais da sociedade ituiutabana. 


\section{Referências:}

ARAÚJO, Jose Carlos; SOUZA, Sauloéber. A escola primária em Minas Gerais e no Triângulo Mineiro (1891-1930). In: ARAÚJO, José Carlos; RIBEIRO, Betânia; SOUZA, Sauloéber (Org.). Grupos escolares na modernidade mineira: Triângulo e Alto Paranaíba. Campinas: Alínea, 2012. p.17-42.

BERNARDES, Vânia Aparecida Martins; "História e Memória: O programa Alfa" in Cadernos de História de Educação, 2002.

BUFFA, Ester; NOSELLA, Paolo. Instituições escolares: porque e como pesquisar. Campinas, SP: Ed. Alínea, 2009. 87 p.

CUNHA, Luiz Antônio. GÓES, Moacir de. O golpe na Educação. Rio de Janeiro: Jorge Zahar Ed., 1985.

DELGADO, Lucília. O Governo João Goulart e o golpe de 1964: memória, história e historiografia. Tempo. 2010, vol.14, n.28, p. 123-143.

FARIA FILHO, Luciano. Dos pardieiros aos palácios: cultura escolar e urbana em Belo Horizonte na primeira República. Universidade de Passo Fundo: Editora UPF, 2000.

FREITAG, Bárbara. Escola, Estado e Sociedade. $7^{\circ}$ ed., São Paulo: Centauro, 2005.

GERMANO, José Willington. Estado Militar e educação no Brasil. $4^{\circ}$ Ed. São Paulo: Cortez, 2005.

ISOBE, Rogéria. Os Grupos Escolares e a Inspeção Técnica do Ensino em Minas Gerais. In: ARAUJO, José Carlos; RIBEIRO, Betânia; SOUZA, Sauloéber. (Org.). Grupos escolares na modernidade mineira: Triângulo e Alto Paranaíba. Campinas: Alínea, 2012, p.65-93.

NUNES, Clarice. Notas de Leitura. Revista Brasileira de Educação, no. 21, Set/Dez, 2002, p. 164-165.

OLIVEIRA, Pedro Affonso. Catalogação e Digitalização de Acervos Paroquiais da Diocese de Ituiutaba. In I Semana de História do Pontal, Ituiutaba-MG. Anais da I Semana de História do Pontal. UFU, 2010, p.11-18.

PAIVA, Vanilda. História da Educação Popular no Brasil: Educação Popular e educação de Adultos. São Paulo: Loyola, 1987.

PINSKY, Carla (org). Fontes Históricas. 2. Ed., São Paulo. Contexto, 2010.

SAVIANI, Dermeval. Escola e democracia. 24. ed., São Paulo: Cortez, 1991.

SANFELICE, José Luis. História, instituições escolares e gestores educacionais. In: Revista HISTEDBR On-line Campinas-SP, n. especial, p.20-27, ago. 2006. 
SOUZA, Sauloéber. O Universo Escolar nas Páginas da Imprensa Tijucana (Ituiutaba-MG - Anos de 1950 e 1960). Cadernos de História da Educação, Uberlândia-MG, vol. 9, n.2, 2010, p.523-541.

SOUZA, Sauloéber; CASTANHO, Sérgio. Instituições escolares e história da educação no Brasil. In SOUZA, Sauloéber; RIBEIRO, Betânia (org.). Do Público ao Privado, do Confessional ao Laico: a história das instituições escolares na Ituiutaba do século XX. Uberlândia-MG, EDUFU, 2009, p.23-44.

\section{Fontes Orais:}

ALVES, Eloisa. Ex-professora do grupo escolar. Entrevista concedida em 11/01/2013, Ituiutaba-MG.

ANDRADE, Dinora. Ex-professora do grupo escolar. Entrevista concedida em em 11/02/2013, Ituiutaba-MG.

CASTRO, Elita. Ex-aluna do grupo escolar. Entrevista concedida em 17/05/2013, Ituiutaba-MG.

MARTINS, Ana. Ex-diretora do grupo escolar. Entrevista concedida em 14/06/2013, Ituiutaba-MG.

MORAES, Salete. Ex-aluna do grupo escolar. Entrevista concedida em 28/11/2012, Ituiutaba MG.

MOURA, Gilsa. Ex-aluna do grupo escolar. Entrevista concedida em 17/05/2013, Ituiutaba-MG.

SILVA, Marina. Ex-aluna do grupo escolar. Entrevista concedida em 28/11/2012, Ituiutaba-MG.

SOARES, Margarida. Ex-professora do grupo escolar. Entrevista concedida em 08/02/2013, Ituiutaba-MG.

\footnotetext{
${ }^{1}$ Sauloéber Tarsio de Souza é professor Associado da Universidade Federal de Uberlândia atua no Programa de Pós-Graduação da FACED-UFU (Linha de História e Historiografia da Educação). É graduado e Mestre em História pela UNESP e Doutor em Educação pela UNICAMP (2005). Rua Ítalo Gentil, 145 - ItuiutabaMG - CEP 38302-152. Email: sauloeber@pontal.ufu.br

Talita Alves Costa é graduada em Pedagogia e mestranda em educação pela Universidade Federal de Uberlândia, desenvolveu projeto de Iniciação Científica em história da educação com apoio da FAPEMIG (2013). Professora do Munícipio de Ituiutaba-MG. Email: talitaalves_itba@ hotmail.com

${ }^{2}$ O decréscimo populacional entre os anos de 1960 e 1970 decorreu da emancipação política de alguns distritos administrados pelo município de Ituiutaba, mesmo assim, o movimento de urbanização fica bastante evidenciado (Fonte: Fundação IBGE - Censos Demográficos dos anos de 1940 a 1970).

${ }^{3}$ No início dos anos de 1960, o presidente João Goulart (1961-1964) durante seu mandato trabalhou na perspectiva de uma democracia social, que segundo Freitag (2005) tinha como objetivo realizar reformas
} 
estruturais, que permitissem a inclusão das massas populares num padrão de consumo democratizado. "Os responsáveis pela deposição de João Goulart foram militares, respaldados por apoio internacional e em parceria com partidos políticos, segmentos e organizações da sociedade civil que se opunham à opção política do presidente e de seus aliados históricos". (DELGADO, 2010, p.143)

${ }^{4}$ Tal proposta adotava ações como a introdução da disciplina de Educação Moral e Cívica e ênfase na Educação Física, tendo como objetivo, segundo Cunha e Góes (1985), preencher o "vácuo ideológico" ocupando a mente dos jovens para que não se juntassem aos opositores do governo. Porém, muitos professores lutaram contra a ideologia oficial imposta nos currículos escolares, usando artimanhas para trabalhar seus conteúdos e desenvolver a crítica, mesmo sob a vigilância ditatorial.

${ }^{5}$ A tabela não trata das mais de 70 escolas isoladas existentes no período na zona rural do município.

${ }^{6}$ Cônego Ângelo, durante o período que atuou na região, liderou diversos atos como construções de estradas, pontes, edifícios públicos, capelas nas vilas e que por muitas vezes assumiu as paróquias de Monte Alegre de Minas e Campina Verde, além de acumular vários cargos políticos. (OLIVEIRA, 2010, p. 16-17)

5 Ana Martins cursou Normal Superior e Pedagogia e mais tarde fez especialização em Supervisão Escolar. Iniciou suas atividades como gestora do Grupo Escolar Cônego Ângelo no ano de 1966, por indicação política.

${ }^{8}$ A ex-aluna Salete Moraes nasceu em 1968, em uma cidade vizinha a Ituiutaba, filha de um operador de máquinas agrícolas mudou-se com a família composta por seis irmãos para as proximidades do grupo escolar, onde concluiu a $4^{\circ}$ série.

${ }^{9}$ Gilsa Moura também era de uma família de trabalhadores, o pai era pedreiro e a mãe lavadeira de roupas. Nasceu em Ituiutaba no ano de 1968, morava com os pais e dois irmãos, ainda na infância, aos oito anos de idade, começou a trabalhar como babá e aos quatorze anos foi trabalhar em um escritório odontológico. 